\title{
Letter to the editor: Does Segmental Kyphosis Affect Surgical Outcome after a Posterior Decompressive Laminectomy in Multisegmental Cervical Spondylotic Myelopathy?
}

\author{
Vibhu Krishnan Viswanathan ${ }^{1}$, Surabhi Subramanian ${ }^{2}$ \\ ${ }^{1}$ Department of Neurological Surgery, Ohio State University, Columbus, OH, USA \\ ${ }^{2}$ Department of Radiology, Government Medical College, Nagpur, India
}

We read with interest the article by Jain et al. [1] titled "Does segmental kyphosis affect surgical outcome after a posterior decompressive laminectomy in multisegmental cervical spondylotic myelopathy?” The article discusses retrospectively analyzed data involving 68 patients who underwent non-instrumented multilevel cervical laminectomy for cervical spondylotic myelopathy (CSM) between 1998 and 2009. It is a well-written article, and the authors' efforts in such a controversial issue are definitely laudable. Some questions however remain:

The authors performed non-instrumented cervical laminectomy in all patients. Although laminectomy may be performed in older patients, particularly in those with serious medical co-morbidities, who have significant anterior osteophytes or partial autofusion, as well as in patients with an ossified posterior longitudinal ligament, isolated laminectomy results in progressive kyphotic deformity. Such kyphosis is known to occur over several years, particularly in younger patients, and has an overall negative impact on spinal biomechanics [2]. The current series included a relatively young population (mean age,
61.88 years; the youngest patient was 41 years old). Do the authors recommend non-instrumented cervical laminectomy as the standard of care even in young patients with CSM? This is in contrast to the general consensus on the definitive need for additional instrumentation, except in the aforementioned situations.

Of 32 patients with preoperative kyphosis, nine (28\%) developed progressive kyphosis (more than $5^{\circ}$ ). Although this did not have an effect on the neurological recovery and final Japanese Orthopaedic Association scores, would the authors also recommend additional fusion in patients with preoperative kyphosis? The authors have not analyzed disability or pain scores, which are known to be affected by cervical sagittal imbalance [3].

The series included patients operated between 1998 and 2009. With the availability of more versatile instrumentation options in the present scenario and better understanding of the importance of sagittal balance and alignment in spinal biomechanics [4], would the authors still consider non-instrumented laminectomy in all patients in the series?

Received Mar 11, 2017; Accepted Mar 12, 2017

Corresponding author: Vibhu Krishnan Viswanathan

Department of Neurological Surgery, The Ohio State University, 410 W, 10th Ave, Columbus, Ohio-43210, USA

Tel: +1-6143023859, E-mail: drvibu007@gmail.com 
The cervical musculature attaches to the $\mathrm{C} 2$ and $\mathrm{C} 7$ vertebrae, and these attachments are essential for maintaining cervical sagittal alignment and lordosis [5]. Even though the authors have taken care to preserve $\mathrm{C} 2$ muscular attachments, the laminectomy was distally extended to the $\mathrm{C} 7$ level in all patients, with further extension of laminectomy across the cervicothoracic junction in 7 patients. This is a deviation from the general understanding that such extensive laminectomy needs to be supplemented with instrumented fusion. Would the authors recommend instrumentation in the subset of patients where laminectomy extended across the cervicothoracic junction?

Did any patient need revision surgeries during followup? How many needed instrumented fusion as a secondary procedure?

There is an error on page 26 in the "Results" section, paragraph 1, lines 18, 19: it is mentioned that an age of $<57$ years negatively correlated with the recovery rate. The overall impression from the article is that younger age is associated with better recovery.

\section{Conflict of Interest}

No potential conflict of interest relevant to this article was reported.

\section{References}

1. Jain A, Rustagi T, Prasad G, Deore T, Bhojraj SY. Does segmental kyphosis affect surgical outcome after a posterior decompressive laminectomy in multisegmental cervical spondylotic myelopathy? Asian Spine J 2017;11:24-30.

2. Kaptain GJ, Simmons NE, Replogle RE, Pobereskin L. Incidence and outcome of kyphotic deformity following laminectomy for cervical spondylotic myelopathy. J Neurosurg 2000;93:199-204.

3. Roguski M, Benzel EC, Curran JN, et al. Postoperative cervical sagittal imbalance negatively affects outcomes after surgery for cervical spondylotic myelopathy. Spine (Phila Pa 1976) 2014;39:2070-7.

4. Cheung JP, Luk KD. Complications of anterior and posterior cervical spine surgery. Asian Spine J 2016; 10:385-400.

5. Ding H, Xue Y, Tang Y, et al. Laminoplasty and laminectomy hybrid decompression for the treatment of cervical spondylotic myelopathy with hypertrophic ligamentum flavum: a retrospective study. PLoS One 2014;9:e95482. 